\title{
Analysis Name Entity Disambiguation Using Mining Evidence Method
}

\author{
Adelya Astari $^{1}$, Moch Arif Bijaksana ${ }^{2}$, Arie Ardiyanti Suryani ${ }^{3}$ \\ ${ }^{1}$ Telkom University Bandung \\ e-mail: aadelyaaastarii@student.telkomuniversity.ac.id \\ ${ }^{2}$ Telkom University Bandung \\ e-mail: arifbijaksana@telkomuniversity.ac.id \\ ${ }^{3}$ Telkom University Bandung \\ e-mail: ardiyanti @ telkomuniversity.ac.id
}

\begin{abstract}
Hadith is the second guideline and source of Islamic teachings after the Qur'an. One of the most Saheeh hadith is the book of Saheeh al-Bukhaari. Hadith Sahih Bukhari has a chain of narrators, hadith numbers, and contents of different contents. This tradition also has science that discusses the history of the narrators of the hadith called the Science of Rijalul Hadith. In the Sahih Bukhari hadith there are the names of the narrators of the hadith who have the same name, causing obligation between names. That makes it difficult for many ordinary people to understand these ambiguous names because it is not yet known whether the two names are the same person or not. So, it raises the problem of a name ambiguation for ordinary people who cannot distinguish whether the name of the narrator is the same person or not. To solve these problems, a solution is built, namely the disambiguation of names to eliminate the ambiguity of the name by checking the name, hadith number, narrators chain, content topics, circles, countries, and companions of the Prophet that are seen from the 3 last names before the Prophet based on the chain of narrators. Also, the solution is assisted by using a method Mining Evidence with several other approaches, i.e. Association label documents, word association labels, context similarity, cosine similarity, and word2vec to obtain all similarity values between name entities. After the similarity values are obtained, the data are grouped using the Clustering algorithm. This system is expected to be able to produce a good system performance with a confusion matrix based on value precision, recall, and accuracy.
\end{abstract}

Keywords: Disambiguation, Entity Name, Mining Evidence, Sahih Bukhari, Similarity

\section{INTRODUCTION}

Hadith is the second guideline and source of Islamic teachings after the Qur'an. One of the most authentic hadith books is the book of Sahih Bukhari because it requires liqa 'or meeting between the narrator and his teacher. Sanad is a series of narratives that deliver death to the Prophet Muhammad. Hadith Sahih Bukhari has knowledge that discusses the history of narrators or narrators of traditions called Ilmu Rijalul Hadith(Chairulloh et al., n.d.). This Hadith has a chain of narrators, hadith number, and contents of different contents. In the Sahih Bukhari hadith there are the names of the narrators of the hadith who have the same name, giving rise to name ambiguation. It makes many ordinary people who find it difficult to understand with an ambiguous name. Because it is not yet known whether the two names are the same person or not. For example, there is the name Naif 'in Hadith number 2338 and Hadith number 2360(Dia et al., n.d.). Both names are the same name if only seen from the name. However, if examined further, not necessarily the two names are the same person. Therefore, a solution was built, namely disambiguation of names to eliminate ambiguity in names by checking the names, hadith numbers, narrators' chains, circles, countries, and companions of the prophet that can be seen from the 3 last names before the prophet based on the narrator's chain. Therefore, the right method as a solution is Mining Evidence which consists of several approaches, namely the association label document, word association label, context Similarity, and word vector(Farnham \& Rowland, 1968) to obtain all the similarity values between name entities. After all the context similarity values are obtained, the data are grouped using the Clustering algorithm(Gupitasari, 2019). The clustering algorithm is used to group data that have a similarity in character or similarity between name entities. This system is expected to produce a good system performance based on the value of precision, recall, and accuracy(Hoffart et al., 2011).

Based on the background description that has been presented, some problems in this final assignment can be formulated such as how to identify the named entity, eliminates the obligation of the named entity, and input the dataset in the form of a set of named entity sets taken from the Sahih Bukhari Hadith 
where the output is the name extraction data has been manually labeled and clustering after getting the similarity value. Of all the problems that have been made, the limitation on this final project is in the form of name entities that are already available for the extraction of names, data taken from Sahih Bukhari and Wikipedia, and only uses Indonesian and English.

The goal to be achieved in this thesis is to build a dataset in the form of the extraction of names from the Hadith Sahih Bukhari. Then, the data is eliminated by using the Mining Evidence method and Cosine Similarity. In addition to knowing the performance of the name disambiguation system with the calculation of precision, recall, and accuracy. As well as grouping using clustering algorithms from the similarity of characteristics or similarity between name entities.

\section{Related Studies}

This section contains the results of theoretical studies conducted by the author. The following theories are the theories used and related to this thesis, such as Named Entity Disambiguation, Mining Evidence, Context Similarity, Cosine Similarity, Document Label Association, Word Label Entity Association, Word2Vec, Confusion Matrix, Clustering (Farnham \& Rowland, 1968).

\section{Name Entity Disambiguation}

Disambiguation of a named entity is (Bunescu \& Pas, n.d.; Farnham \& Rowland, 1968) the process of identifying names that refer to the same entity in a context, in order to eliminate the ambiguity of two entities of the same name.

\section{Datasets}

The data set used was taken from a collection of 101 Sahih Bukhari's hadiths(Dia et al., n.d.). Hadith data is manually labeled to be extracted as a dataset. Other data used is taken from Wikipedia on a website (text input) as much as 50 data.

\section{Mining Evidence}

Mining Evidence (Farnham \& Rowland, 1968) is a method used as proof of an entity's name, whether the same or not based on existing data. Mining Evidence functions to increase the value of data performance in the process of eliminating the obligation of named entities.

\section{Context Similarity}

Context Similarity(Cucerzan, 2007; Farnham \& Rowland, 1968) is the process of calculating the value of similarity as a comparison of entities in a text. Where the named entity is built a text that is related to the word representation. The approach used in this process is the label word association.
The approach has a relationship between an entity with the word representation or a relationship formation between an entity with the word representation. The results of the entity label word association in the form of word vector or representation of the content of the hadith.

\section{Cosine Similarity}

Cosine Similarity (Bunescu \& Pas, n.d.; Farnham \& Rowland, 1968; Guntara, 2019) is a method for calculating the similarity between two vectors or documents in a vector space. The calculation is done by calculating the cosine angle of each pair of word vectors. If a vector document with a vector query is the same then the document can be seen increasingly in accordance with the query. The equation for calculating cosine similarity between two vectors is as in equation 1 .

$$
\operatorname{Sim}=\cos (\theta)=\frac{A \cdot B}{\|A\| \cdot\|B\|} \ldots \ldots \ldots \ldots \ldots . .(1)
$$

Description :

$\mathrm{A}=$ document

$\mathrm{B}=$ query

Two-word vectors in an entity that has similarities are likely to have high similar values. Similaritybased on the cosine similarity method gives a better recommendation if the value of $\operatorname{sim}(\mathrm{a}, \mathrm{b})$ is between 0.0 and 1.0. Value 1.0 indicates that the two entities are the same.

\section{Word2Vec}

Word2Vec(Gupitasari, 2019) is the process of predicting target words based on their context in order to get the value of similarity Word2Vec using cosine similarity. Word2Vec can process words from very large datasets in a relatively short time with better accuracy.

\section{Document Label Association}

Document Label Association (Farnham \& Rowland, 1968 ) is the process of labeling an entity that represents the document to get the value of similarity. Label provisions can be seen from the topic of the document. Document-label associations help express entity labels for labeled documents.

\section{Label Entity Association}

Label Entity Word Association (Farnham \& Rowland, 1968) is a process of labeling name entities to calculate the estimated value of each word that has been labeled in order to get a similarity value. The higher the value, the word has lost its ambiguity.

\section{Confusion Matrix}

Confusion matrix (Chairulloh et al., n.d.; Ginting et al., n.d.) is one method that can be used to measure the performance of a system with the classification method or referred to as a confusion matrix. The confusion matrix is a representation of the results of 
the classification process in the form of actual and predicted values. In performance measurement using the confusion matrix, there are 4 terms as a representation of the results of the classification process. The four terms are True Positive (TP), True Negative (TN), False Positive (FP) and False Negative ( $F N)$ (Chairulloh et al., n.d.). Table 1 shows the terms from the table confusion matrix.

Tabel 1. Confusion Matrix

\begin{tabular}{|c|c|c|}
\multicolumn{1}{c}{} & \multicolumn{2}{c|}{ Actual } \\
\cline { 2 - 3 } \multicolumn{1}{c|}{ Prediction } & Positive & Negative \\
\hline Positive & TN & FP \\
\hline Negative & FN & TP \\
\hline
\end{tabular}

Sumber : (Ginting et al., n.d.)

Score True Negative (TN) is the amount of negative data that was detected correctly, whereas False Positive (FP) is negative data but detected as positive data, True Positive (TP) is positive data that was detected correctly and False Negative (FN) is the opposite of True Positive, so the data is positive, but detected as negative data.

By utilizing the terms of the method confusion matrix is able to get value precision, recall, and accuracy. In equations 2,3, and 4 are the Calculations confusion matrix.

\section{Precision}

Precision (Chairulloh et al., n.d.; Hoffart et al., 2011) is used to measure the accuracy of the system in determining the relevant documents in the search for documents received, in other words the result of precision is the value of the ability of the system in making decisions. The formula below is a calculation precision.

Description :

$$
\text { Precision }=\frac{T P}{T P+F P}
$$

$\mathrm{TP}=$ True Positive

$\mathrm{FP}=$ False Positive

\section{Recall}

Recall (Chairulloh et al., n.d.; Cucerzan, 2007; Hoffart et al., 2011) is used to measure the accuracy of the system in determining relevant documents in search of all relevant documents, in other words the result of recall is the value of the accuracy of the system to get the actual relevant documents. The formula below is a calculation recall.

Description :

$$
\text { Recall }=\frac{T P}{T P+F N}
$$

TP $=$ True Positive

$\mathrm{FN}=$ False Negative

\section{Accuracy}

Accuracy (Farnham \& Rowland, 1968) is used to get the accuracy of decision making by the system to determine the relevance of documents. As for how to calculate accuracy.

$$
\text { Accuracy }=\frac{T P+T N}{T P+T N+F P+F N} \text {. }
$$

Description :

$\mathrm{TP}=$ True Positive

$\mathrm{TN}=$ True Negative

$\mathrm{FP}=$ False Positive

$\mathrm{FN}=$ False Negative

\section{Clustering}

Clustering (Gupitasari, 2019) is a method used to group data to produce a data representation that represents a pattern formed by the relationships that exist between the data. Clustering is an unsupervised machine learning method, where the collection of words in other words that have similar characteristics based on the similarity function for calculating the distance of words. As for several methods of clustering, namely $k$-Means.

K-Means (Gupitasari, 2019)is a method of partition clustering and aims to minimize data objects with a number of $\mathrm{k}$ centroids.

\section{RESEARCH METHOD}

The system built aims to eliminate the ambiguity of the same name entity using the Mining Evidence method and Cosine Similarity(Farnham \& Rowland, 1968) in order to get the value of similarity. Figure 1 is the stages carried out in eliminating the ambiguation of a named entity:

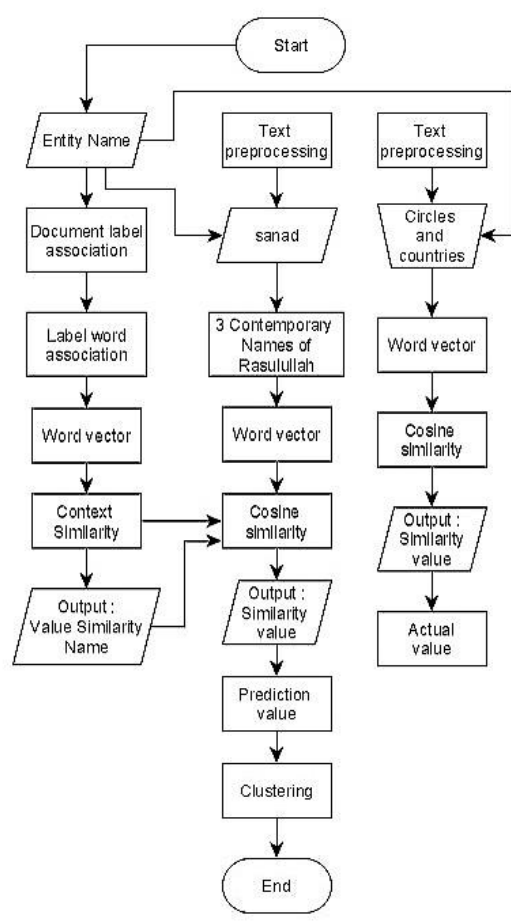

Picture 1. System Overview 
The picture above has 3 processes. The first process is the name extraction for each entity obtained from the Bukhari Hadith. Extraction is done manually using the document label association and the word association label. The extraction produces narrators' data. The second process, is the result of extraction in the form of narrator chain data from the first process. The narrator's chain was re-processed to get a friend's name who was a contemporary of the Prophet Muhammad. The process of getting it by sorting each named entity that has a chain of narrators with the suffix Rasulullahhu'alaihi wassalam. Then, take 3 last names before the Messenger of Allah. The process can be seen in 4 . The third process, is the result of extraction in the form of data between the state based on name entities. The results of all three processes, each one is processed using the cosine similarity and word vector methods to get the similarity value. The similarity value is in order to get the actual and predicted values using the confusion matrix. As the results of the hadith data are grouped based on the same name entity using the clustering and a scatter plot algorithm. While the Wikipedia data uses a clustering algorithm with k-means and scatter plot approaches to visualize the grouping.

\section{Context Similarity}

This process uses the word association label(Farnham \& Rowland, 1968) approaches obtained from the results of the text preprocessing. Another approach used is to consider the topic of the text of a hadith number.

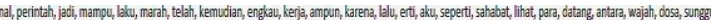
dan, bila, shallallathu, tawwe, paling, allah, balian

Sumber : (Dia et al., n.d.)

\section{Picture 2. Hadith Data Extraction Result}

Picture 2 is an example of the word association label extraction results. These results are in the form of unique words that represent ambiguous name entities, then proceed by using Cosine Similarity to get the context similarity value with a range of values between 0 and 1 .

\section{Text Preprocessing}

Text preprocessing (Farnham \& Rowland, 1968; Guntara, 2019) is the stage of selecting the data to be processed. In Figure are the stages of text preprocessing which are divided into three processes.

The first process is the extraction of the name or word association label obtained from the Hadith Sahih Bukhari. The process is carried out for each named entity, in order to extract the contents of the hadith in accordance with the number of the hadith. Then a step is made that changes all the letters in the document to lowercase and eliminates punctuation, or referred to as a folding case. Next, process filtering or stoplist by removing words that are less

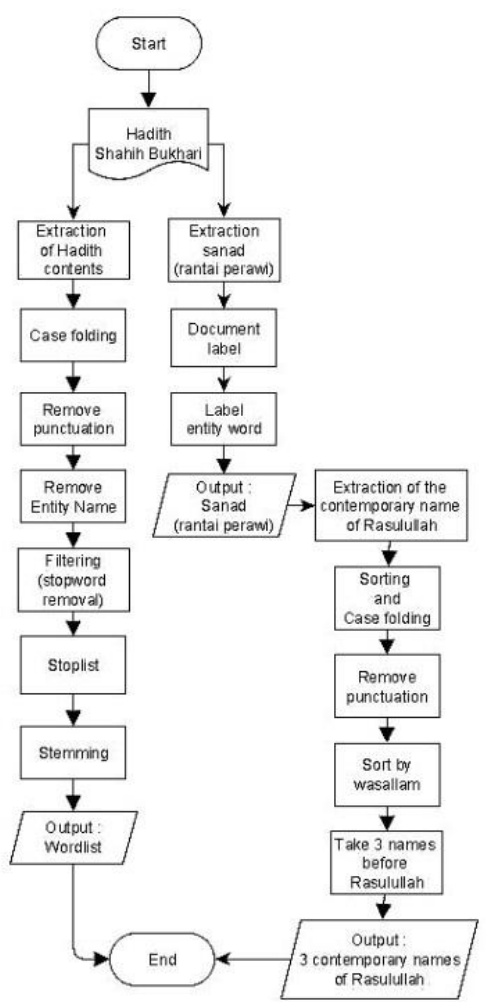

Picture 3. Text Preprocessing Process

important to connect an entity with the same word representation so as to produce output in the form of unique words from the text of the hadith. The process is called stemming.

The second process is the extraction of the chain of narrators, wherein this process the data is labeled manually, to separate the entity names, hadith numbers, and chain of narrators from the hadith text. From this output, to obtain names that are already unambiguous are taken based on the same-named entity. The third process, namely getting a contemporary name with the Messenger of Allah, which is obtained from the chain of narrators. This is done based on the science of hadith. Figure 3 is an example explanation of the process of getting 3 names that were contemporary with the Messenger of Allah.

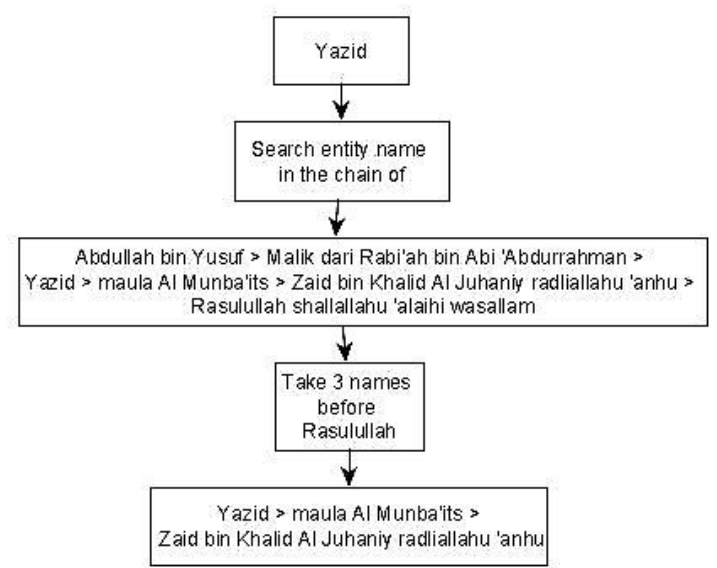

Picture 4. The Process of Obtaining The Name of Rasulullah 
Tabel 2. Hadith Data Testing Result

\begin{tabular}{|c|c|c|c|c|c|c|c|c|}
\hline \multicolumn{9}{|c|}{ Hadith Data Testing Result } \\
\hline & $\begin{array}{l}\text { Hadith } \\
\text { Number }\end{array}$ & Content & Topic & Circles & Country & Contemporary & Prediction & Actual \\
\hline Abdul Wahid & 2326 & 0,6 & 0 & 1 & 1 & 1 & $\mathrm{Y}$ & $\mathrm{Y}$ \\
\hline Abdul Wahid & 2316 & 0,4 & 0 & 1 & 1 & 1 & $\mathrm{Y}$ & Y \\
\hline Abdul Wahid & 122 & 0,5 & 0 & 1 & 1 & 1 & Y & Y \\
\hline Ibnu Umar & 59 & 0,4 & 1 & 1 & 1 & 1 & $\mathrm{Y}$ & $\mathrm{Y}$ \\
\hline Ibnu Umar & 80 & 0,4 & 0 & 1 & 1 & 1 & Y & $\mathrm{Y}$ \\
\hline Ibnu Syihab & 5278 & 0,4 & 0 & 1 & 0,9 & 1 & $\mathrm{Y}$ & $\mathrm{Y}$ \\
\hline Ibnu Syihab & 2283 & 0,4 & 0 & 1 & 1 & 1 & Y & $\mathrm{Y}$ \\
\hline Ibnu Syihab & 23 & 0,4 & 0 & 1 & 1 & 1 & $\mathrm{Y}$ & $\mathrm{Y}$ \\
\hline Maula & 2251 & 0,5 & 1 & 1 & 1 & 1 & $\mathrm{Y}$ & Y \\
\hline Maula & 2249 & 0,4 & 1 & 1 & 0,9 & 1 & $\mathrm{Y}$ & $\mathrm{Y}$ \\
\hline Maula & 2256 & 0,3 & 1 & 1 & 1 & 1 & $\mathrm{Y}$ & $\mathrm{Y}$ \\
\hline Nafi' & 2338 & 0,5 & 1 & 0.7 & 1 & 1 & $\mathrm{Y}$ & $\mathrm{Y}$ \\
\hline Nafi' & 2360 & 0,4 & 0 & 0.75 & 0 & 0 & $\mathrm{~N}$ & $\mathrm{~N}$ \\
\hline Nafi' & 2311 & 0,3 & 0 & 0.4 & 0 & 0 & $\mathrm{~N}$ & $\mathrm{~N}$ \\
\hline Qutaibah & 2409 & 0,2 & 0 & 1 & 1 & 1 & Y & $\mathrm{Y}$ \\
\hline Qutaibah & 2319 & 0,2 & 0 & 0 & 0 & 0 & $\mathrm{~N}$ & $\mathrm{~N}$ \\
\hline Outaibah & 59 & 0,3 & 0 & 1 & 1 & 1 & $\mathrm{Y}$ & $\mathrm{Y}$ \\
\hline Yazid & 2251 & 0,4 & 1 & 1 & 1 & 1 & $\mathrm{Y}$ & $\mathrm{Y}$ \\
\hline Yazid & 2249 & 0,8 & 1 & 1 & 0,88 & 1 & $\mathrm{Y}$ & $\mathrm{Y}$ \\
\hline Yazid & 2256 & 0,4 & 1 & 1 & 1 & 1 & $\mathrm{Y}$ & Y \\
\hline
\end{tabular}

From the picture 4, to find out the same name entity friends who are contemporaries with the Messenger of Allah or not can be seen by looking at the chain of narrators of the name entities ending in the Prophet. Then do the checking by sorting the last 3 names before Rasulullah. Sorting based on the word wasallam. From the results of the last 3 names obtained, compared each entity to get the similarity value.

\section{Contemporaries}

Contemporaries (Chairulloh et al., n.d.)are at the same time or at the same time. In this process an examination of the two entities with the same name from the Prophet's companions, circles, and countries of origin obtained from the hadith encyclopedias. In the same name entity, friends, circles, and countries are examined by cosine similarity to get an output value of 1 if friends, circles, and countries are the same or output 0 if friends, circles, and countries are different.

\section{RESULTS AND DISCUSSION}

In this section explains the analysis of test results and system test results.

\section{Test Result}

The testing process was carried out using test data totaling 101 data from the text preprocessing data of the Hadith Sahih Bukhari(Dia et al., n.d.). From 101 data where each name consists of several of the same names. For example there is the name $\mathrm{Na}^{\prime} \mathrm{f}$ in the hadith number 2338 , the number hadith 2360 , and the number hadith 2311. The name entities are tested with each other to eliminate the obligation of the name.

The following attached table 2 is some of the results of testing that has been done for Hadith data. There is a name, hadith number, context of the content, context of the topic, circles, country, contemporary, prediction, and actual. This is an example of some of the results of a hadith test data of 100 test data

Other testing processes use Wikipedia data as much as 50 data obtained from the Wikipedia Market (text input). Tests on wiki data are not much different from hadith data, both of which aim to eliminate the obligation of a named entity. From 50 data where each name consists of several names that have the same prefix. The name cannot be said to be the same even though the prefix name looks the same. So, the writer explores further from the text. For example, there is the name of Michael Jordan with Michael B Jordan (Farnham \& Rowland, 1968). The name entities are tested with each other to eliminate name ambiguation with the cosine similarity and word vector methods to get the value of similarity or similarity between entities.f the hadith contained in the appendix.

Table 3 on the below for Wikipedia data consist of number, title, comparison(Comp) between entity names, data of an entity, context name $(\mathrm{CN})$, context of the content $(\mathrm{CC})$, actual(A), and prediction(P). This is an example of some of the results of a Wikipedia test data of 50 test data. 
Tabel 3. Wikipedia Data Testing Result

\begin{tabular}{|c|c|c|c|c|c|c|}
\hline \multicolumn{7}{|c|}{ Wikipedia Data Testing Result } \\
\hline & Compare & Data & Context Name & Context of Content & Actual & Prediction \\
\hline Bryan Cranston & Bryan Spicer & American actor, film & 0,5 & 0,30 & $\mathrm{~N}$ & $\mathrm{Y}$ \\
\hline Bryan Spicer & Bryan Adams & American film, singer & 0,5 & 0,32 & $\mathrm{~N}$ & $\mathrm{Y}$ \\
\hline Bryan Adams & Bryan Cranston & Singer, Actor & 0,5 & 0,69 & Y & Y \\
\hline David R Ellis & David Lynch & Film director, film maker & 0,4 & 0,6 & Y & $\mathrm{Y}$ \\
\hline David Lynch & David Fincher & Film director, film maker & 0,5 & 0,7 & $\mathrm{Y}$ & Y \\
\hline David Beckham & David Villa & Professional footballer & 0,5 & 0,7 & $\mathrm{Y}$ & $\mathrm{Y}$ \\
\hline James Gandolfini & James Dean & American actor & 0,5 & 0,6 & $\mathrm{Y}$ & $\mathrm{Y}$ \\
\hline James Dean & James Woods & American actor & 0,5 & 0,7 & $\mathrm{Y}$ & $\mathrm{Y}$ \\
\hline John Cusack & John Stamos & American actor & 0,5 & 0,5 & $\mathrm{Y}$ & $\mathrm{Y}$ \\
\hline John Stamos & John Wayne & American actor & 0,5 & 0,6 & $\mathrm{Y}$ & $\mathrm{Y}$ \\
\hline John Wayne & John Cusack & American actor & 0,5 & 0,6 & $\mathrm{Y}$ & $\mathrm{Y}$ \\
\hline Kevin Spacey & Kevin Costner & American actor & 0,5 & 0,6 & Y & Y \\
\hline Kevin Martin & Keith Urban & Singer & 0,40 & 0,49 & $\mathrm{Y}$ & Y \\
\hline Peter Coyote & Peter Berg & Director, Actor & 0,5 & 0,665 & $\mathrm{Y}$ & $\mathrm{Y}$ \\
\hline Robert Aldrich & Robert Duvall & Actor, Director & 0,5 & 0,54 & $\mathrm{Y}$ & $\mathrm{Y}$ \\
\hline Ribert Duvall & Robert Z. Leonard & American actor & 0,40 & 0,58 & $\mathrm{Y}$ & $\mathrm{Y}$ \\
\hline Michael Jackson & Michael Bolton & American singer & 0,5 & 0,6 & Y & $\mathrm{Y}$ \\
\hline Michael Jordan & Michael B.Jordan & Basketball player & 0,8 & 0,6 & $\mathrm{Y}$ & $\mathrm{Y}$ \\
\hline Tom Cruise & Tom Hanks & American actor & 0,5 & 0,7 & $\mathrm{Y}$ & $\mathrm{Y}$ \\
\hline William Hanna & Will Graham & Animator, Character & 0 & 0,55 & $\mathrm{Y}$ & $\mathrm{N}$ \\
\hline
\end{tabular}

Based on the overall results of the test data, then use the confusion matrix to get the value of precision, recall, and accuracy. Table 4 results of Hadith data. Table 5 results of Wikipedia data. The tables are a combination of predicted values and actual values.

Tabel 4. Result Confusion Matrix Hadith Data

\begin{tabular}{|c|c|c|}
\cline { 2 - 3 } \multicolumn{1}{c}{ Prediction } & Actual \\
\cline { 2 - 3 } & Positive & Negative \\
\hline Positive & 16 & 7 \\
\hline Negative & 9 & 70 \\
\hline
\end{tabular}

The table above shows the results of the matrix of the hadith data. Truth Positive (TP) hadith data of 70 names that were predicted to be the same person. Truth Negative (TN) Hadith data of 16 names that were predicted to be true were different people. False Positive (FP) Hadith data as many as 7 names that are predicted to be wrong are different people in the actual also prediction. False Negative (FN) hadith data as many as 9 people who are the same but predicted as different people.

Tabel 5. Result Confusion Matrix Wikipedia Data

\begin{tabular}{|c|c|c|}
\multicolumn{1}{c}{ Prediction } & \multicolumn{2}{c|}{ Actual } \\
\cline { 2 - 3 } & Positive & Negative \\
\hline Positive & 0 & 4 \\
\hline Negative & 7 & 40 \\
\hline
\end{tabular}

Table 5 shows the matrix results from Wikipedia data.
Truth Positive (TP) wiki data of 40 names that were predicted to be the same person. Truth Negative (TN) Wiki data of 0 names that were predicted to be true were different people. False Positive (FP) Wiki data of 4 names that are predicted to be wrong are different people in the prediction as well as actual. False Negative ( $F N)$ wiki data of 7 same people but predicted as different people.

\section{Analysis of Test Result}

The results of this test indicate the existence of the same name entity values varying with the given threshold of more than 0.4 to 1 . The threshold applies to the results of the hadith and Wikipedia data. The results of this test are obtained from the actual and predicted values to get precision, recall, and accuracy. Attached to table 6 is the result of a systematic evaluation of Hadith data and Wikipedia data consist of TN, FP, FN, TP, Precision, Recall, and Accuracy. (Farnham \& Rowland, 1968; Hoffart et al., 2011; Nguyen \& Cao, 2008).

Tabel 6. Evaluation Result

\begin{tabular}{|l|l|l|l|l|l|l|l|}
\cline { 2 - 8 } \multicolumn{1}{c|}{} & TN & FP & FN & TP & Prec & Rec & Acc \\
\hline Hadith & 16 & 7 & 9 & 70 & 0.9 & $\begin{array}{l}0.84 \\
3\end{array}$ & 0.843 \\
\hline Wiki & 0 & 4 & 7 & 40 & 0.9 & 0.85 & 0.8 \\
\hline
\end{tabular}

Judging from the test, that the evaluation results using confusion matrix, where the value of precision, recall, and accuracy approaching $100 \%$ is high because the combined results of the predicted value, the actual value and can also be seen in Truth Positive (TP), 
False Positive (FP), False Negative (FN) and True Negative (TN).

The results of the confusion matrix show that the values of precision, recall, and accurately predicted by the system are the same person. These results apply to the data of the Hadith. That is because two entities have the same name if people and countries are the same, it can be ascertained that these two names are contemporaneous with the Messenger of Allah. Therefore, the average actual value can reach more or less $80 \%$.

In Wikipedia data, the values of precision, recall, and accuracy are the same person. Because the two name entities being compared are thought to have fields and text that are similar, the result of similarity is also high.

Factors that influence the predictive value of the Hadith data, namely the value of similarity and threshold. The resulting similarity value is very small because the word list that accompanies each named entity is unique. The threshold used for prediction values is more than 0.4 because it is based on experiments of several values, with a threshold

0.4 obtained the best prediction results.

Another factor that influences the predictive value of Wikipedia data is the threshold. Because the name entities in Wikipedia only have the same prefix name. Thus, the similarity value for the name is very small. Thus, additional professional data and text from each named entity are used to obtain high similarity and accuracy values. In this data, the threshold provisions used are the same as the date of the Hadith.

From the above test, this system produces an average value of precision of 0.9 , an average value of recall of 0.8 , and an average accuracy value of 0.8 . The value obtained shows that the same name entity is the same person and also this system is good enough because the value obtained is high. As a result of the system, the hadith data and wiki data are grouped according to the class each entity uses.

In calculating performance on Hadith data and Wikipedia data. The calculations used are precision, recall, accuracy and the confusion matrix is the actual value and predictive value. Predictive value is obtained from the combined results of the context value similarity, topic, and narrator contemporaries with the Prophet. The pre-determined and actual values have two outputs, namely the output "Y" for the overall value more than the threshold or " $\mathrm{N}$ " for the overall value less than the threshold. The threshold is a level of similarity of more than 0.4 obtained from the results of several value experiments. If the overall value is greater than the threshold, then the two entities with the same name are the same person. If the overall value is less than the threshold, then the two entities with the same name are different people. Then for the actual value obtained from the same circles and countries for each entity name. If, circles and countries are the same, then it can be ensured that the entity is the same as the Prophet.

\section{Clustering}

The clustering process is carried out to classify a Hadith data and Wikipedia data in order to produce a data representation that is formed due to existing relations between the data. The data used is obtained from the results of the similarity that has been done. So that objects that have the same similarity are grouped in the same cluster and objects that have different similarities are grouped into another cluster. Picture 5 is the result of clustering, visualization of the hadith data.

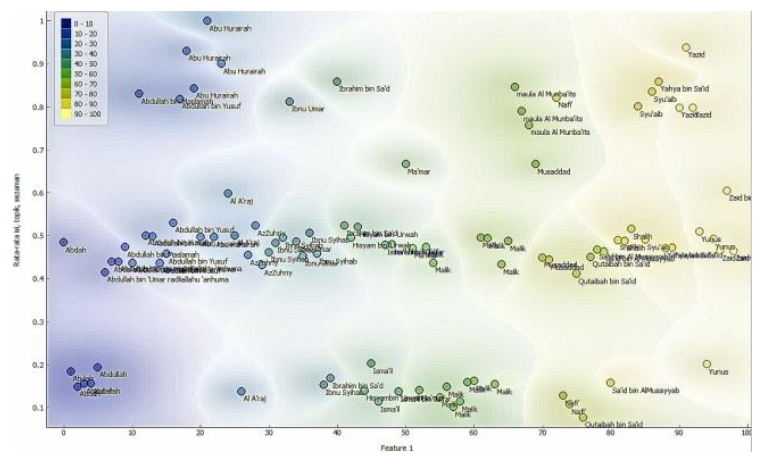

Picture 5. Clustering of Hadith Data

Data it is formed where the collection of words with other words that have similar characteristics based on the similarity function for calculating the distance of these words.

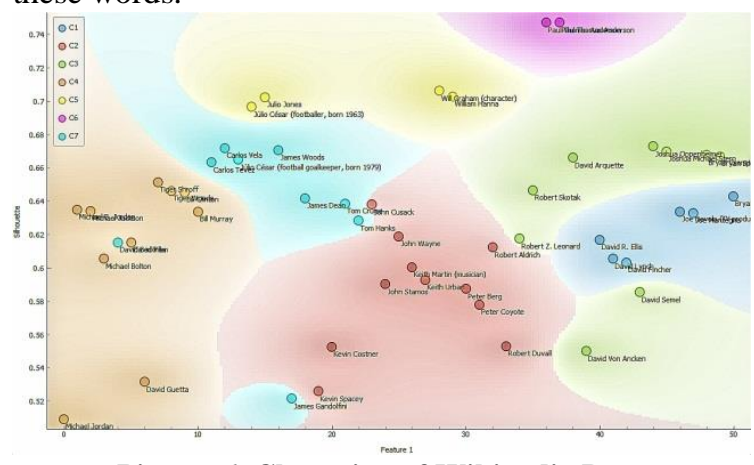

Picture 6. Clustering of Wikipedia Data

Picture 6 is the result of the Wikipedia data cluster. Data grouping is taken based on the same similarity value without calculating other values such as actual and predicted values. Clustering grouping is assisted with a k-means approach which aims to minimize data objects with a number of $\mathrm{k}$ centroids using scatter plots as visualization. So that the grouping can be seen based on the color and similarity results for each entity with the same name. 


\section{CONCLUSION}

The conclusion that can be drawn from the test results is the performance of the system to eliminate the ambiguation of a named entity from the Sahih Bukhari Hadith and text input from Wikipedia Page using the cosine similarity method to obtain a confusion matrix value from the similarity results(Farnham \& Rowland, 1968). From these results it shows that the system has obtained values of precision, recall, accuracy with a threshold of more than 0.4 . Thus, the average accuracy obtained is 0.8431372549 for hadith data and 0.8 for Wikipedia data. The final data can then be grouped by Name entity using a clustering algorithm. This shows that the system performance is good. In this test, the data presented are only 101 hadith from the many hadith of Bukhari, and 50 Wikipedia texts from many other Wikipedia.

Suggestions for further development is the need for the addition of hadith and Wikipedia data to further improve the performance of this system. Because the accuracy value can vary depending on a lot of data used.

\section{REFERENCE}

Bunescu, R., \& Pas, M. (n.d.). Using Encyclopedic Knowledge for Named Entity Disambiguation.

Chairulloh, M. R., Bijaksana, M. A., \& Wahyudi, B. A. (n.d.). Analisis Name Matching untuk Nama Arab Menggunakan Metode N-gram dan Jaccard Similarity Pendahuluan Studi Terkait Hadis Pedoman Transliterasi Aksara Arab ke Latin. 1-7.

Cucerzan, S. (2007). Large-scale named entity disambiguation based on Wikipedia data. EMNLP-CoNLL 2007 - Proceedings of the 2007 Joint Conference on Empirical Methods in Natural Language Processing and Computational Natural Language Learning, June, 708-716.

Dia, L., Maka, M., \& Tidak, S. (n.d.). No Title.

Farnham, J. E., \& Rowland, R. E. (1968). The retention of $133 \mathrm{Ba}$ in beagles. ANL-7615.
ANL [Reports]. U. S. Atomic Energy Commission, 32-38.

Ginting, M. F., Bijaksana, M. A., Wahyudi, B. A., \& Telkom, U. (n.d.). Analisis Pencocokan Nama Arab Dengan Terjemahan Nama Indonesia Menggunakan Metode Jaro Winkler.

Guntara, F. F. (2019). Pembangunan Daftar Kata Terkait pada Kosa Kata Al-Qur ' an Berdasarkan Kesamaan Distribusiaonal Proposal Tugas Akhir Program Studi Sarjana Informatika Fakultas Informatika Universitas Telkom Bandung.

Gupitasari, L. (2019). Pembangunan Synonym Set untuk Tesaurus Al-Quran dengan Pendekatan Kamus Monolingual dan WordNet Proposal Tugas Akhir Program Studi Sarjana Informatika Fakultas Informatika Universitas Telkom Bandung.

Hoffart, J., Yosef, M. A., Bordino, I., Fürstenau, H., Pinkal, M., Spaniol, M., Taneva, B., Thater, S., \& Weikum, G. (2011). Robust disambiguation of named entities in text. EMNLP 2011 - Conference on Empirical Methods in Natural Language Processing, Proceedings of the Conference, 782-792.

Nguyen, H. T., \& Cao, T. H. (2008). Named entity disambiguation on an ontology enriched by Wikipedia. RIVF 2008 - 2008 IEEE International Conference on Research, Innovation and Vision for the Future in Computing and Communication Technologies, $00(\mathrm{c})$, 247-254. https://doi.org/10.1109/RIVF.2008.4586363

\section{AUTHOR PROFILE}

Adelya Astari, the year 2018 graduated from the University of Telkom Informatics Management Diploma Program in Bandung. Currently, he is continuing his bachelor's degree in Informatics Engineering from Telkom University. 